\title{
O Estado da Arte da Pesquisa Brasileira em Psicologia do Trabalho e Organizacional ${ }^{1}$
}

\author{
Jairo Eduardo Borges-Andrade ${ }^{2}$ \\ Cecília do Prado Pagotto \\ Universidade de Brasília
}

\begin{abstract}
RESUMO - Este texto revisa sistematicamente os artigos científicos, publicados no Brasil, sobre o fazer humano no trabalho e gestão de pessoas nas organizações. A análise leva em conta o campo profissional no País, a pós-graduação e os periódicos nacionais e a produção internacional. Seus parâmetros são as questões relacionadas ao método, ao conteúdo e aos beneficiários da produção que foi publicada. Finaliza apresentando uma proposta de agenda estratégica para a pesquisa brasileira, com base nas informações analisadas.
\end{abstract}

Palavras-chave: comportamento organizacional; gestão de pessoas; produção intelectual; atuação profissional; pós-graduação.

\section{The State of the Art of Brazilian Research on Work and Organizational Psychology}

\begin{abstract}
This paper systematically reviews the scientific articles, published in Brazil, on human doing at work and personnel management in organizations. The analysis takes into account the professional field in the Country, the national graduate courses and journals, and the international production. Issues related to method, content and beneficiaries of the published production are used as parameters for the analysis. Based on the analyzed data, a strategic agenda for Brazilian research is finally proposed.
\end{abstract}

Keywords: organizational behavior; personnel management; intellectual production; professional practice; graduate studies.

A Psicologia Organizacional e do Trabalho (PO\&T) ou a Psicologia do Trabalho e das Organizações $(\mathrm{PT} \& \mathrm{O})^{3}$ pode ser definida como (1) subárea de conhecimento e (2) campo de aplicação de conhecimentos ou de intervenção. Como subárea do conhecimento, tem o fazer humano enquanto objeto de estudo e os contextos do trabalho e das organizações como locais desse estudo. Como campo de aplicação ou intervenção, precisa dar respostas a questões práticas concernentes a interações entre o comportamento humano, o trabalho e as organizações onde este comportamento pode ocorrer, bem como a questões relacionadas às práticas dessas organizações.

Aquela subárea e este campo podem passar por processos específicos de desenvolvimento, respectivamente relacionados à pesquisa científica e à atuação profissional. Precisarão periodicamente estabelecer contatos que permitam que produção e utilização do conhecimento caminhem mais ou menos juntas e que mútuos benefícios possam emergir. Esses benefícios mais facilmente emergirão se existirem aqueles contatos. A pesquisa brasileira raramente ocorre no campo

1 O presente texto reúne dados apresentados pelo primeiro autor numa mesa redonda e numa conferência realizadas por ele no IV Congresso Brasileiro de Psicologia Organizacional e do Trabalho, em São Bernardo do Campo, 2010.

2 Endereço para correspondência: Depto. de Psicologia Social e do Trabalho, Instituto de Psicologia, Universidade de Brasília. Brasília, DF. CEP 70910-900.E-mail: jairo@unb.br.

3 Essas denominações serão aqui utilizadas como sinônimos e suas siglas serão mencionadas, de modo intercalado, ao longo do presente texto. profissional e na pós-graduação lato sensu. Portanto, o lócus para que os mencionados contatos ocorram é a pós-graduação stricto sensu e sua produção está disponível em periódicos científicos. O presente texto tem como objetivo revisar a produção intelectual realizada na subárea de conhecimento PT\&O ou PO\&T. Antes disso, apresenta alguns dados sobre o campo de aplicação PO\&T ou PT\&O (profissionais de psicologia) e sobre onde ocorre a produção da sua subárea de conhecimento (pós-graduação) e onde ela é divulgada (periódicos científicos).

\section{O Campo de Aplicação e a Subárea de Conhecimento}

O campo de aplicação ou de intervenção em PT\&O deve utilizar o conhecimento gerado pela pesquisa, para solucionar problemas relacionados ao comportamento humano no trabalho, à interação entre esse comportamento e a organização onde ocorre, e às práticas utilizadas para organizar a ação individual e a coletiva, visando atingir determinados objetivos (Zanelli \& Bastos, 2004).

Recente pesquisa publicada (Gondim \& Bastos, 2010) sobre a atuação dos psicólogos revelou que, no campo do "trabalho" e das "organizações" (Gondim, 2009), 83\% dos profissionais são mulheres, residentes no sudeste $(49 \%)$, sul $(23 \%)$, nordeste (17\%) e centro-oeste (10\%). Seus principais locais de atuação profissional são escritórios, consultórios ou residências (37\%), empresas privadas 
(23\%) e empresas e órgãos públicos (8\%). Metade combina vínculos assalariados com trabalho autônomo, um terço tem somente vínculos assalariados e 14\% são só autônomos.

Do total dos estudados naquela pesquisa, uma amostra de mais de 4.000 psicólogos brasileiros, 23\% só atuam em PO\&T, sendo este o segundo campo de dedicação exclusiva, logo após o campo de atuação da "clínica" (41\%). Há, ainda, $12 \%$ daquele total que combinam PT\&O com outros campos de atuação. É um contingente bastante expressivo, especialmente em termos relativos, pois $62 \%$ dos que atuam em PO\&T o fazem em dedicação integral, enquanto essa dedicação varia entre $51 \%$ e $19 \%$ em outros campos como clínica, saúde, escolar e docência, por exemplo.

Dentre as atividades desenvolvidas em PT\&O, ainda de acordo com Gondim (2009), predominam, de modo cumulativo, a aplicação de testes psicológicos e psicodiagnósticos (61\%), avaliação de desempenho (53\%) e diagnóstico organizacional (50\%), seguidos de atividades relacionadas à gestão (23\%), análise de função ou ocupacional (22\%) e recrutamento e seleção (19\%). Outras atividades, menos frequentes, são as concernentes à dinâmica de grupo (16\%), ao desenvolvimento de grupos e equipes (16\%), à reabilitação profissional (13\%), análise de cargos e salários (13\%) e intervenção organizacional (12\%).

Essas atividades são principalmente realizadas em grupos multidisciplinares, quando os profissionais estão no terceiro setor ou no setor público. No setor privado, elas geralmente são realizadas nesses grupos ou individualmente, enquanto a grande maioria dos autônomos não as realiza em grupos, sejam estes multi ou unidisciplinares. Dois terços têm rendimentos entre três e nove salários mínimos. Mais de dois terços não declaram intenção de sair do campo de atuação da PO\&T, o que sugere que, além de numericamente expressivo, este é estável e pode se beneficiar de forma perene da produção resultante da sua subárea de conhecimento.

Predominam os profissionais cuja titulação é a graduação (45\%), seguidos dos que fizeram especialização (39\%). Em número bem modesto, estão os titulados em pós-graduação stricto sensu: mestres e doutores (16\%). Gondim (2009) revela, finalmente, que as competências que mais necessitam ser desenvolvidas, entre esses profissionais, são as de realizar diagnósticos organizacionais e de processos psicológicos de grupos, de coordenar tais processos e realizar pesquisas em geral.

Ao comparar os dados de atuação profissional com a produção intelectual relatada nos II e III Congressos Brasileiros de Psicologia Organizacional e do Trabalho, realizados nos anos de 2006 e 2008, respectivamente, a mencionada autora conclui que existe relativa congruência entre essa produção intelectual e o que se faz no campo da PT\&O, mas que não é produzido conhecimento suficiente para dar suporte ao que o profissional realiza com mais frequência. O que dizer da pós-graduação stricto sensu em PO\&T no Brasil, que é supostamente o local onde aquelas competências poderiam ser desenvolvidas pela maioria dos profissionais e que também é o espaço no qual muito provavelmente ocorre a produção intelectual?

Há mais de 60 programas de pós-graduação stricto sensu em psicologia no Brasil, que oferecem cursos nos níveis de mestrado e doutorado (Associação Nacional de Pesquisa e Pós-graduação em Psicologia - ANPEPP, 2010). O crescimento dessa pós-graduação criou oportunidades para áreas de concentração, linhas e projetos de pesquisa. Entre 1996 e 2007, o número desses programas saltou de 24 para 53, sendo que o maior crescimento $(35,8 \%)$ ocorreu entre 1998 e 2001 (Lo Bianco, Almeida, Koller \& Paiva, 2010). Essa pós-graduação precisa ultrapassar “o estágio em que pesquisadores são formados para a Universidade, para um novo estágio em que pesquisadores também são formados para outros setores da sociedade..." (FéresCarneiro, Bastos, Feitosa, Seidl-de-Moura \& Yamamoto, 2010, pp. 12-13). Isso é necessário para que os mais diversos segmentos da sociedade possam ser plenamente beneficiados pelo que é produzido nos programas de pósgraduação em psicologia.

No final do século passado, uma análise dos programas de pós-graduação em psicologia levou à conclusão de que o campo da PT\&O constituía uma das duas maiores lacunas nacionais (Borges-Andrade, 2001). A evolução do mencionado campo, nos 10 anos seguintes, parece ter reduzido essa lacuna (Féres-Carneiro \& cols., 2010). Esse campo conta hoje com 18 programas de pós-graduação (Tabela 1). Essa quantidade parece ser equivalente ao percentual dos profissionais que atuam no campo, mas é preciso analisar o que eles efetivamente formam e produzem.

Tabela 1. Programas de pós-graduação stricto sensu no Brasil, com áreas de concentração ou linhas de pesquisa ou docentes que têm produção intelectual e desenvolvem atividades de orientação relacionadas à Psicologia do Trabalho e das Organizações (Fonte: Associação Brasileira de Psicologia Organizacional e do Trabalho - SBPOT, 2010).

\section{Universidade}

Pontifícia Universidade Católica de Goiás

Universidade de Brasília

Universidade de Fortaleza

Universidade de São Paulo (Ribeirão Preto)

Universidade de São Paulo (São Paulo)

Universidade do Estado do Rio de Janeiro

Universidade Federal da Bahia

Universidade Federal de Minas Gerais

Universidade Federal de Santa Catarina

Universidade Federal de São João del-Rei

Universidade Federal de Uberlândia

Universidade Federal do Ceará

Universidade Federal do Rio Grande do Norte

Universidade Federal do Rio Grande do Sul

Universidade Metodista de São Paulo

Universidade Salgado de Oliveira

Universidade São Francisco

Universidades Federais da Paraíba \& Rio Grande do Norte (integrado) 
Dentre esses programas, há dois casos (Universidade de Brasília e Universidade de São Paulo, São Paulo) em que as palavras "trabalho" ou "organizações" são usadas para qualificar suas próprias áreas de concentração. Em dois terços desses programas, elas se apresentam na descrição das suas linhas de pesquisa. No terço restante, elas aparecem em projetos integrantes de algumas linhas de pesquisa. Uma porção relevante dos docentes que fazem pesquisa e ensino nesses programas de pós-graduação, participa de redes de investigação formadas pelos Grupos de Trabalho (GTs) da Associação Nacional de Pesquisa e Pós-graduação em Psicologia - ANPEPP (Tabela 2).

Nos últimos Simpósios de Pesquisa e Intercâmbio Científico em Psicologia, cinco GTs foram mantidos e um novo apareceu em 2010 (número 6 na Tabela 2). Em quatro dos que foram mantidos nos anos mais recentes, ocorreu pouca alteração nas temáticas centrais, embora novos assuntos tenham sido incorporados na maioria. É, portanto, uma evidência de relativa estabilidade nos interesses de investigação daqueles docentes que atuam em redes de pesquisa apoiadas pela ANPEPP.

A subárea PO\&T estuda o fazer humano, verificado direta ou indiretamente, considerando seus estados subjetivos, em contextos de organizações e trabalho (Zanelli \& Bastos, 2004). O mencionado fazer humano pode incluir comportamentos, relações entre pessoas e grupos, disposições, motivos, percepções, crenças, reações, atitudes, significados, valores e sentimentos. Também está interessada em investigar o seu próprio campo de intervenção, ou as práticas relativas à gestão de pessoas, dentre as quais se destacam a seleção, a avaliação de desempenho (AD) e o treinamento e desenvolvimento (T\&D).

O que essa subárea gera serve aos profissionais ou estudantes. Eles necessitam conhecer os fundamentos e as suposições inerentes àquele fazer humano e às práticas de intervenção. Não deveriam confiar na especulação ou em evidência baseada em contos e ficção, para tomar decisões nos contextos de trabalho e organizacional (Borges-Andrade \& Zanelli, 2004). Esses autores assinalam que a PT\&O não está apenas interessada em mensurar e descrever fazeres humanos e práticas. Está interessada no "como" e no "porquê" naqueles contextos. Busca pesquisar para conhecer os antecedentes e consequentes dos fenômenos que estuda, ou como eles dependem de características dos níveis individual, grupal, organizacional e da sociedade em geral.

Os desafios que essa pesquisa precisa enfrentar incluem (Borges-Andrade \& Zanelli, 2004):

1) encontrar uma definição e os indicadores para os fenômenos que pretende investigar;

2) medir e descrever os seus possíveis antecedentes e consequentes;

3) encontrar contextos em que possam ser demonstrados padrões de variação desses antecedentes e consequentes;

4) ter em conta que aqueles fenômenos podem ser modificados por esses contextos e também modificá-los.

Essa pesquisa passou, no século XX, por três etapas de evolução dos seus métodos de investigação, conforme indica a análise das publicações do Journal of Applied Psychology (Austin, Scherbaum \& Mahlman, 2002). O primeiro intervalo (1904 a 1935) pode ser denominado de "estabelecimento" da subárea de conhecimento. Medidas de habilidades e interesses vocacionais foram utilizadas como preditores de desempenho produtivo, medido por escalas de razão, em pequenas amostras de trabalhadores. As análises predominantes foram descritivas e correlacionais, com pequeno número de variáveis. Esses resultados deveriam servir aos gestores. A

Tabela 2. Grupos de Trabalho da Associação Nacional de Pesquisa e Pós-graduação em Psicologia, atuantes nos Simpósios de Pesquisa e Intercâmbio Científico de 2008 e 2010, na subárea de Psicologia Organizacional e do Trabalho (Fonte: ANPEPP, 2010).

\section{Simpósio de Pesquisa e Intercâmbio Científico em Psicologia - 2008}

1. Trabalho e saúde (com base na psicodinâmica do trabalho, ergonomia da atividade e sociologia clinica); organização do trabalho e violência psicológica no serviço público brasileiro.

2. Ócio, tempo e trabalho.

3. Trabalho, desemprego e processos de exclusão social; autogestão e cooperativismo; trabalho, subjetividade e saúde; cotidiano e processos organizativos; trajetórias e memórias do trabalho.

4. Bem-estar e cultura organizacional.

5. Ocupação, qualificação, trabalho em equipe, identidade, significado, comprometimento, bem-estar, burnout, aprendizagem, valores.

\section{Simpósio de Pesquisa e Intercâmbio Científico em Psicologia - 2010}

1. Trabalho e saúde (com base na psicodinâmica do trabalho, ergonomia da atividade e sociologia clínica).

2. Ócio, tempo e trabalho.

3. Formas de inserção no trabalho, desemprego e processos de exclusão social; autogestão e cooperativismo; identidades, subjetividades e produção de sentidos no trabalho; cotidiano e processos organizativos; trajetórias, carreiras e memórias do trabalho; trabalho, subjetividade e saúde.

4. Saúde e bem-estar no trabalho, em suas dimensões individuais e culturais.

5. Pessoas, trabalho e organizações, intervenções a partir da Psicologia, sob os eixos norteadores do desempenho, relações de trabalho e avaliação de programas; afetos e cognições no trabalho e nas organizações.

6. Modos de vida e trabalho. 
melhor palavra para caracterizar o segundo intervalo, de 1936 a 1968, seria "expansão". A maior parte do moderno arsenal em medidas, desenho de pesquisa e análise de dados foi desenvolvida nessa época. A pesquisa continuou voltada para os gestores e, em menor grau, para os trabalhadores. O excesso de informações, entre 1969 a 2000, caracterizou o terceiro período por ser de “eutrofização". A grande complexidade dos métodos de pesquisa diminuiu a capacidade das audiências tradicionais (gestores e trabalhadores) entenderem o que é produzido e como é produzido. A pesquisa passou a ser voltada para os pesquisadores, gerando o risco de uma gradual diminuição da relevância da subárea para outras audiências.

A pesquisa produzida nos programas de pós-graduação e nos grupos de trabalho que eles formam pode ser divulgada em livros e periódicos científicos. Ao contrário de outras áreas das ciências humanas e sociais, na psicologia, os livros e capítulos de livros são menos frequentes que os artigos em periódicos (Hutz, Rocha, Spink \& Menandro, 2010). O atual sistema de avaliação dos programas da CAPES/MEC tende a valorizar mais estes que aqueles. De acordo com Lo Bianco e cols. (2010), 73\% dos artigos em PO\&T foram publicados em periódicos nacionais. A presente revisão tem o foco nesses periódicos, atualmente bem mais disponíveis que os livros. Seu acesso é livre na Internet, por conta de requisitos desse sistema de avaliação. Até $70 \%$ da produção da pós-graduação em PT\&O, divulgada em periódicos nacionais, ocorre em periódicos mantidos por entidades e cursos vinculados à área da administração, e não da psicologia (Borges-Andrade, Coelho Jr \& Queiroga, 2006; Borges-Andrade \& Meira, 2003). Como essa produção está organizada nesses periódicos?

Sete periódicos brasileiros em psicologia (rPOT, Psicologia \& Sociedade, Estudos de Psicologia - Natal, Psicologia em Estudo, Psicologia: Reflexão e Crítica, Psicologia: Teoria e Pesquisa, Psicologia - USP), que publicaram artigos relacionados a PO\&T, foram analisados por Tonetto, Amazarray, Koller e Gomes (2008). Eles encontraram 178 artigos, entre 2001 e 2005, correspondendo a 16\% do total de artigos publicados nesses periódicos. Diagnosticaram essa produção como sendo grande e diversificada, com predomínio de temas relacionados a comportamento organizacional (20\%); seguidos por avaliação e medidas; trabalho, identidade e subjetivação; trabalho e saúde e gestão de pessoas (cada um com $11 \%)$. A maioria dos seus autores está vinculada à psicologia em instituições de ensino (UnB, 20\%; UFRGS e UFSC, 7\% cada; UFRN, 5\%; UCB e UFBA, 4\% cada).

A maior pluralidade de subtemas foi encontrada em comportamento organizacional. Em gestão de pessoas, foram identificados raríssimos artigos sobre seleção e a maioria concentrada em treinamento e desenvolvimento de pessoas e carreiras. Os focos de atenção estiveram divididos ao meio: questões organizacionais e de trabalho como formadores do psiquismo humano. Isso, provavelmente, refletindo os efeitos da nova organização do trabalho na ordem social (desemprego e exclusão) e nas práticas de autogestão e saúde.

Ao analisarem aspectos metodológicos, Tonetto e cols. (2008) encontraram que 30\% dos artigos eram somente teóricos, enquanto 70\% eram de natureza teórico-empírica. Nesses casos, $47 \%$ adotaram uma abordagem quantitativa e $37 \%$, qualitativa, enquanto $16 \%$ combinaram ambas abordagens. Essa pesquisa foi voltada tanto para subsidiar o planejamento e a execução de intervenções, quanto o desenvolvimento teórico da subárea. Boa parte dessa produção trata o trabalho como elemento central no processo concernente à formação de identidade.

Nas referências bibliográficas desses artigos, apareceram $36 \%$ de autores nacionais e igual percentual de autores internacionais. As mistas representaram 29\%. Curiosamente, as referências a autores nacionais ficaram concentradas em livros, enquanto as referências a autores internacionais ficaram concentradas em artigos. Os artigos com o foco em comportamento organizacional e em trabalho e saúde foram os que mais citaram diferentes áreas do conhecimento.

Ao contrário da psicologia brasileira, a área da administração brasileira publica artigos completos em periódicos e também em anais de eventos científicos. Portanto, uma análise com foco em artigos divulgados em administração não poderia ignorar tais eventos, mesmo que eles ultimamente tenham perdido sua importância na avaliação dos programas de pós-graduação. Essa produção (em seis periódicos: RAC, RAE, RAUSP, RAP, O\&S e REAd; em três eventos: EnANPAD, ENEO e 3E) foi analisada por Rossoni (2006), no período entre 1997 e 2005 . O autor diagnosticou que o número de artigos aumentou significativamente, principalmente em anais completos de eventos, graças ao crescimento da pós-graduação. A produção sobre comportamento organizacional ( $n=419)$, quando comparada à produção em gestão organizacional $(n=312)$, é mais elevada (especialmente em anais), dispõe de um maior número de autores por artigo e utiliza, majoritariamente, a abordagem quantitativa. Entretanto, a segunda (gestão organizacional) tende a aparecer mais em periódicos. Os autores de comportamento organizacional e gestão organizacional passaram a publicar com mais frequência numa terceira vertente, que é de natureza "macro": estratégia organizacional.

Rossoni (2006) apontou que a produção voltada para comportamento e gestão organizacionais era divulgada, nesses periódicos e anais, por autores com vínculos institucionais com a psicologia. Ele encontrou que essa produção se concentra num certo número de autores e identificou um aumento na quantidade de artigos produzidos por autor. Contudo, mais de $60 \%$ dos autores identificados publicaram uma única vez no período investigado. Autores isolados são somente $12 \%$ do total, nos anos investigados. Cresceu a cooperação entre autores em geral e estes estão mais produtivos. A cooperação cresceu mais entre autores que têm produções elevadas e intermediárias. Essa cooperação ocorre com mais intensidade no sentido de dividir tarefas para escrever um texto. Há menos cooperação entre autores para produzir mais artigos. Além disso, há mais relações de autoria entre estudantes e professores, do que entre estes últimos.

Além de realizar essas análises, Rossoni (2006) avaliou as redes formadas entre os autores e encontrou que os tamanhos delas e dos laços entre esses quase duplicaram. Ao mesmo tempo, as redes perderam densidade, pois os autores passaram a estar mais conectados fora de seus grupos, por meio de poucos intermediários. Entretanto, autores centrais aumentaram seus relacionamentos no período. O número de grupos nas redes cresceu enormemente (de nove para 66) e esse aumento foi maior do que o crescimento das redes. Foram ampliadas substancialmente as instituições dos autores e 
as temáticas que investigam, embora estas sejam homogêneas dentro desses grupos. Autores com maior produção foram os que se relacionaram com mais colaboradores e com mais grupos nas redes.

A produção intelectual da PO\&T divulgada em artigos científicos publicados em periódicos de psicologia e administração é o foco da análise das próximas duas seções, sendo priorizada a produção nacional. No caso da produção internacional, serão mencionadas revisões recentes divulgadas por um meio que privilegia quadros teóricos de referência da psicologia, e não da administração, embora os artigos citados nessas revisões muitas vezes tenham sido divulgados em periódicos internacionais de administração. Essa análise será feita em termos dos objetos de estudo, métodos de investigação, veículos de divulgação e supostos beneficiários. No final, será proposta uma agenda estratégica para a pesquisa nacional em PT\&O.

\section{Pesquisa sobre o Fazer Humano no Trabalho}

Revisões de literatura sobre PO\&T aparecem nos volumes anuais do "Annual Review of Psychology" desde 1950. Contudo, essas revisões, até quase o final da década de 1960, incluíam tanto a investigação sobre o fazer humano no trabalho, quanto a voltada para a gestão de pessoas. $\mathrm{O}$ estudo do fazer humano no trabalho passou a ser separada e sistematicamente revisado na década de 1970, primeiro com o nome de atitudes e motivação no trabalho, e depois em revisões denominadas "Comportamento Organizacional", embora o foco destas pudesse ser tanto em contextos de "trabalho" quanto de "organizações". Em meados da década de 1990, provavelmente por conta da intensificação das publicações e da natureza mais específica de alguns temas, essas revisões passaram a ser divulgadas de forma vocacionada para equipes, motivação, burnout, afeto, cognição e violência e agressão.

O Comportamento Organizacional (CO), reconhecido como disciplina independente na década de 1970, surgiu em um espaço de convergência entre áreas do conhecimento já estabelecidas, tais como psicologia, economia e sociologia. Tal multidisciplinaridade em seu cerne certamente contribuiu para que, ainda na atualidade, a mencionada disciplina se apresentasse de forma complexa e difusa (Siqueira, 2002). No entanto, ocorreram sinais de consolidação, como a contínua produção de revisões (Brief \& Weiss, 2002; Gelfand, Erez \& Aycan, 2007; Hodgkinson \& Healey, 2008; O’Reilly, 1991; Rousseau, 1997; Wilpert, 1995). Parte dessa consolidação pode ser atribuída à relativa frequência com que as teorias de psicologia social marcam presença em $\mathrm{CO}$, apesar de este ser aquele espaço de convergência já mencionado.

A sua evolução foi marcada, principalmente, por tentativas de determinação dos níveis de sua estrutura e definição das variáveis que compõem o tema (Siqueira, 2002). Essa autora menciona uma primeira definição de $\mathrm{CO}$ aparecida na década de 1960, formulada como o estudo da estrutura e do funcionamento de organizações e do comportamento de indivíduos e grupos nelas inseridos. Nesse conceito foram inicialmente propostos quatro níveis de análise de estudo: os indivíduos, as equipes ou grupos de trabalho, os depar- tamentos ou setores da organização e as organizações de modo geral; e quatro categorias de variáveis: as relativas ao meio ambiente, aos objetivos/recursos, à estrutura/processos e ao comportamento avaliado. Staw (1984) apresentou um novo conceito para o campo e duas grandes áreas de estudo: macro CO, que tem como foco a própria organização e seu contexto, e micro CO, cujo interesse são as atitudes e os comportamentos individuais e a relação destes com os sistemas organizacionais.

Após várias décadas de pesquisa internacional no campo de CO e de sua estruturação em três níveis de análise - os indivíduos (micro), as equipes e grupos de trabalho (meso) e a organização como um todo (macro) -, a apresentação das suas variáveis tem se dado pela relação com esses atributos. Para Siqueira (2002), faltam discussões sobre o escopo do campo, seu objeto de estudo, normas de aferição de variáveis e posicionamento da sua relação com outras disciplinas mais tradicionais. Três recentes revisões internacionais de pesquisas em $\mathrm{CO}$, todas vocacionadas para subtemas, foram relativas ao afeto no trabalho (Brief \& Weiss, 2002), cognição nas organizações (Hodgkinson \& Healey, 2008) e CO transcultural (Gelfand, \& cols., 2007). Elas serão resumidas a seguir, pois sugerem tendências que precisam ser levadas em conta pelos pesquisadores brasileiros que decidirem investigar temas relacionados ao fazer humano no trabalho.

O estudo sobre afeto no ambiente de trabalho teve seu desenvolvimento a partir da década de 1930, entretanto o período considerado entre 1930 até a década de 1990 não foi muito fértil para esses estudos (Brief \& Weiss, 2002). Considerando, inicialmente, a satisfação profissional como um dos componentes do afeto no trabalho, a crítica surgida a partir da década de 1990 apresentou questionamentos sobre o estado afetivo de satisfação profissional, suas causas, definições e medições. Pesquisas recentes concentraram-se no humor e nas emoções no trabalho, com ênfase sobre situações estressantes, dirigentes, equipes, ambiente físico, recompensas e punições. Outros estudos abordaram como estados afetivos podem influenciar uma variedade de resultados de desempenho relevantes, incluindo julgamentos, respostas atitudinais, criatividade e comportamentos de ajuda. Brief e Weiss (2002) argumentam que o estudo sobre os afetos em trabalho e organizações é limitado no que tange aos métodos. Isso teria levado a uma super ênfase no estudo do humor, em detrimento às emoções discretas (raiva, felicidade, culpa, ciúmes, orgulho).

A pesquisa internacional sobre cognição em trabalho e organizações teve desenvolvimento relevante nas últimas décadas, de acordo com Hodgkinson e Healey (2008). Os estudos sobre cognição foram divididos, na revisão desses autores, em 10 campos: seleção e $\mathrm{AD}$, equipes de trabalho, T\&D, saúde ocupacional e estresse no trabalho, motivação, suporte ao trabalho e ergonomia cognitiva, liderança, processos de tomada de decisão, desenvolvimento e mudança organizacional e diferenças individuais. Os avanços, no que se refere aos métodos e técnicas de análise, foram significativos. Os autores descrevem tensões a serem enfrentadas: cruzar as tradições de pesquisa e os domínios teóricos, integrá-los, compreender as tensões entre as pesquisas de laboratório e de campo e construir metodologias mistas. Os desafios estão em pensar a melhor forma de capturar, representar e interpretar a 
cognição em trabalho e organizações, utilizando a pluralidade de perspectivas teóricas existentes.

O CO transcultural refere-se ao estudo das similaridades e diferenças transculturais nos processos e comportamento no trabalho e às dinâmicas das interfaces transculturais em contextos multiculturais e internacionais (Gelfand \& cols., 2007). Nas pesquisas são investigadas a relação entre cultura e fenômenos micro-organizacionais (motivos, cognições, emoções), meso (equipes, liderança, negociação), macro (cultura organizacional, estrutura) e o inter-relacionamento entre tais níveis. Para esses autores, novos paradigmas de pesquisa são necessários, nesses estudos transculturais, para que ocorram mudanças fundamentais. Apesar de a globalização ter aumentado a facilidade e escopo de interações transculturais nos ambientes de trabalho, estas seriam um fenômeno antigo. Recentes são as pesquisas que começaram a se desenvolver principalmente nas últimas duas décadas, impulsionadas pelo desenvolvimento das taxonomias de valores culturais, crenças e normas e com a combinação de perspectivas emic e etic.

O que pode ser dito sobre a pesquisa brasileira em $\mathrm{CO}$ ? Para responder esta pergunta, foram revisados relatos de pesquisas publicados em 14 periódicos de psicologia e administração (Tabela 3), no período entre 1996 e 2009. Eles foram identificados e registrados como foi descrito por Coelho Jr e Borges-Andrade (2004) e Souza, Vasconcelos e Borges-Andrade (2009).

O levantamento dos artigos nesses periódicos é feito e atualizado há muitos anos, seguindo procedimentos e indicadores de classificação padronizados (Disciplina Comportamento Organizacional, 2010). É realizado por meio de uma parceria entre docentes e discentes de pós-graduação na Universidade de Brasília, Universidade Salgado de Oliveira (Campus de Niterói, RJ) e Universidade Federal da Bahia. Foram encontrados 424 artigos em 14 anos, numa distribuição anual (Figura 1) que teve uma mudança expressiva de patamar nos primeiros anos do século XXI. Essa mudança provavelmente é consequência das novas exigências impostas pela CAPES, no seu sistema de avaliação, relativas à produção intelectual dos programas de pós-graduação brasileiros.

A seleção dos artigos identificados nesse levantamento obedeceu a critérios prévios. As publicações deveriam ser relatos de resultados de pesquisas realizadas no Brasil, em que o objeto de estudo, pelo menos uma variável de micro

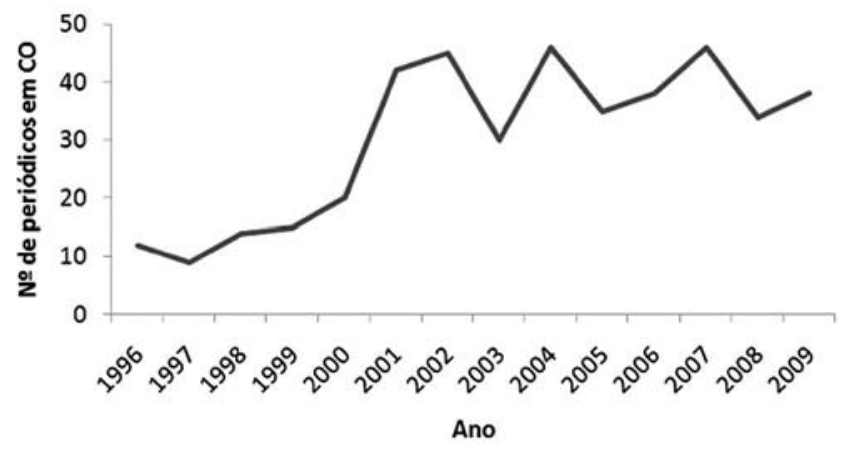

Figura 1. Artigos sobre CO encontrados em 14 periódicos nacionais de administração e psicologia.

CO (Staw, 1984), estivesse clara. Essas variáveis foram, em seguida, classificadas conforme as categorias (Tabela 4) formuladas com base nas revisões sobre CO publicadas desde a metade do século passado no Annual Review of Psychology.

Os artigos classificados estão na Tabela 5. Em termos gerais, embora ainda sem levar em conta o que foi efetivamente investigado, boa parte das 10 temáticas mais frequentes também foram objeto de revisões internacionais recentes.

Em seguida, foi realizada a leitura dos artigos e sua análise, por uma sucessão de pares de juízes, estudantes de mestrado e doutorado previamente treinados, e validada em anos subsequentes por outros juízes, também estudantes de mestrado e doutorado previamente treinados. O método utilizado para análise dos artigos, em 14 anos, foi o descrito por Borges-Andrade e cols. (2006), Borges-Andrade e Meira (2003), Coelho Jr e BorgesAndrade (2004) e Souza e cols (2009). Por meio desse método, foram gradativamente acrescentados e corrigidos dados numa mesma planilha, sobre artigos publicados em anos sucessivos até 2009. Isso ocorreu pela última vez no primeiro semestre de 2010. Os critérios para essa análise estão apresentados na Tabela 6.

Considerando os dados existentes na Tabela 5, há predomínio de estudos com o foco em afeto no trabalho, cuja distribuição anual está na Figura 2. Esses estudos cresceram em número, especialmente depois de 2004. Dentre eles, os assuntos que mais apareceram foram sofrimento e prazer, emoções e satisfação no trabalho. Tais artigos relatam, na sua grande maioria, estudos de caso de natureza descritiva.

Tabela 3. Periódicos nacionais utilizados no levantamento de relatos de pesquisa sobre CO (n=14).

\begin{tabular}{ll}
\hline Periódicos de Administração & Periódicos de Psicologia \\
\hline Revista Administração USP - RAUSP & Estudos Psicologia (UFRN) \\
Revista Administração Empresas - RAE (FGV-SP) & Psicologia: Reflexão e Crítica (UFRS) \\
Revista Administração Pública - RAP (FGV-RJ) & Psicologia em Estudo (UEM) \\
Organizações e Sociedade - O\&S (UFBA) & Estudos Psicologia (PUC Campinas) \\
Revista Administração Contemporânea - RAC (ANPAD) & Psicologia: Teoria e Pesquisa (UnB) \\
& Psico USF \\
& Psico PUCRS \\
& Psicologia, Ciência e Profissão (CFP) \\
& Psicologia: Organizações e Trabalho - rPOT (SBPOT) \\
\hline
\end{tabular}


Tabela 4. Categorias de variáveis critério utilizadas para classificar os relatos de pesquisa sobre CO encontrados em periódicos nacionais.

Afeto no trabalho (satisfação, inveja, ciúme, humor, prazer, sofrimento)

Aprendizagem no posto de trabalho e promovida por T\&D e mentoria e sua transferência para outros indivíduos ou para outros desempenhos

Atitudes frente a mudanças organizacionais (percepção e crenças, resistência, reação e adaptação)

Clima organizacional

Cognição no trabalho (auto gerenciamento e estabelecimento de objetivos, percepções de justiça, equidade, suporte e imagens organizacionais)

Competências no trabalho e nas organizações

Fuga e esquiva do trabalho (intenções ou ações relacionadas a rotatividade, absenteísmo, mobilidade e licenças)

Contratos psicológicos no trabalho (comprometimento afetivo, normativo, calculativo e comportamental, entrincheiramento, envolvimento ou lealdade organizacional, ocupacional, sindical e com a equipe, cidadania ou civismo, espontaneidade, comportamentos pró sociais como cooperação e ajuda, confiança e vulnerabilidade psicológica)

Criatividade e solução de problemas no trabalho e nas organizações

Cultura organizacional (crenças, valores, ritos, símbolos e percepção)

Desempenho produtivo de indivíduos, gerentes e equipes nas organizações e no trabalho

Desvios de comportamento no trabalho (roubo, corrupção, violência, assédios moral e sexual, chantagem, intriga, retaliação e comportamentos workaholic)

Bem-estar e saúde no trabalho (bem-estar, estresse, burnout, abuso de álcool e outras drogas, LER/DORT)

Interações sociais nas equipes e nas organizações de trabalho (interações membro-membro, comunicação, negociação, liderança, poder, conflito, socialização, redes sociais, diversidade)

Motivação no trabalho

Identidade e significados do trabalho, dos seus produtos (centralidade e valores, significado de produtos tangíveis e intangíveis)

Tomada de decisão (gerencial, técnica, de líderes) e julgamentos (sobre subordinados, pares ou superiores) no trabalho

Tabela 5. Distribuição quantitativa dos relatos de pesquisa sobre CO encontrados em periódicos nacionais, em termos das categorias de variáveis critério utilizadas para classificá-los.

\begin{tabular}{ll}
\hline Variáveis critério estudadas & $\mathbf{n}$ \\
\hline Afeto no trabalho & 64 \\
Aprendizagem no trabalho e resultante de T\&D & 49 \\
Interações sociais nas equipes e nas organizações & 47 \\
Bem-estar e saúde no trabalho & 44 \\
Identidade e significados do trabalho e de seus produtos & 44 \\
Cognição no trabalho & 43 \\
Contratos psicológicos & 38 \\
Atitudes frente a mudanças organizacionais & 37 \\
Desempenho produtivo de indivíduos, gerentes e equipes & 34 \\
Cultura organizacional & 32 \\
Competências no trabalho e nas organizações & 16 \\
Clima organizacional & 9 \\
Desvios de comportamento no trabalho & 9 \\
Tomada de decisão e julgamentos no trabalho & 9 \\
Motivação no trabalho & 7 \\
Fuga e esquiva no trabalho & 3 \\
Criatividade e solução de problemas & 3 \\
\hline
\end{tabular}

Num segundo patamar aparecem as pesquisas sobre aprendizagem (principalmente os efeitos de T\&D e a autoaprendizagem no posto de trabalho), interações sociais (principalmente as interações membro-membro e a liderança), bem-estar e saúde (especialmente estresse), identidade e significados (frequentemente centralidade e valores no trabalho) e cognição (predominantemente percepção de justiça e equidade no trabalho), cujas distribuições anuais estão nas Figuras 3 a 7. Dentre essas, estão num lento crescimento as publicações sobre bem-estar e saúde (Figura 5), enquanto as demais (Figuras 3, 4, 6 e 7) tiveram períodos de crescimento e decréscimo nos últimos 14 anos. Nessas cinco categorias de estudos, embora ainda existam muitas investigações de natureza descritiva, há evidências de avanços na testagem de modelos teóricos por meio de pesquisa de natureza inferencial. Isso ocorre especialmente em aprendizagem decorrente de T\&D, valores e percepção de justiça e equidade no trabalho.

Num terceiro patamar estão os estudos sobre contratos psicológicos (com destaque para comprometimentos e cidadania organizacionais), atitudes frente a mudanças (especialmente percepção de mudanças), desempenho

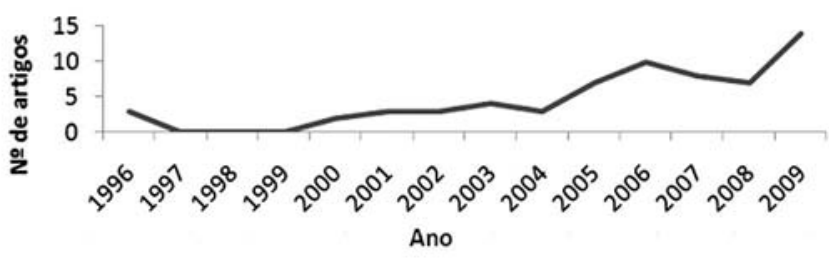

Figura 2. Artigos sobre afeto no trabalho encontrados em 14 periódicos nacionais de administração e psicologia. 
Tabela 6. Critérios de análise dos relatos de pesquisa sobre CO encontrados em periódicos nacionais.

\section{Critérios de Análise}

Instituição de vínculo do(s) autor(es)

Produção ocorrida em programa de pós-graduação stricto sensu

Grau de Escolaridade do(s) Autor(es)

Área de Titulação do(s) Autor(es)

Natureza do Estudo

Desenho da Investigação

Natureza da Pesquisa

Finalidade do Estudo

Natureza da Amostragem

Origem dos Dados Coletados

Procedimento de Coleta de Dados

Procedimento de Análise de Dados

Setor Estudado

Segmento da Economia

produtivo (geralmente eficiência) e cultura organizacional (primordialmente crenças e valores). Nessas quatro categorias de estudos (Figuras 8 a 11), não é possível identificar padrões claros de crescimento ou decréscimo. Ocorreram avanços relevantes quanto à realização de investigação de caráter inferencial, visando a testagem de modelos teóricos, nos casos dos estudos sobre contratos psicológicos e crenças e valores organizacionais. Faltaram referenciais teóricos claros, ou sistematicamente utilizados, nos estudos sobre atitudes frente a mudanças e desempenho produtivo. As demais categorias são pouco frequentes, com menos de dois artigos publicados em cada um dos 14 anos. Portanto, não há informações suficientes para analisar os seus padrões de desenvolvimento quantitativo ou qualitativo.

A produção intelectual sobre o fazer humano no trabalho e suas categorias de variável critério, aparentemente tiveram

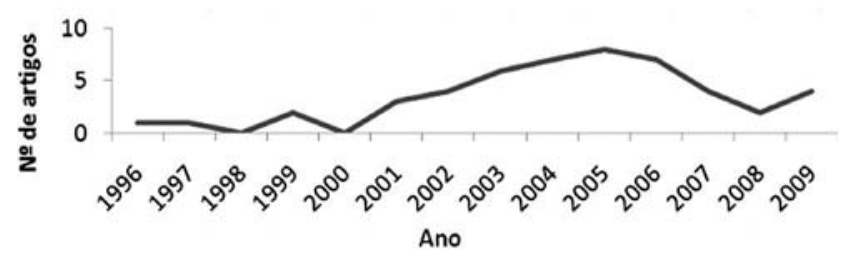

Figura 3. Artigos sobre aprendizagem no trabalho e resultante de T\&D encontrados em 14 periódicos nacionais de administração e psicologia.

\section{Características Analisadas}

Nome da organização de vinculação

Dissertação de Mestrado, Tese de Doutorado

Graduando, Graduado, Mestrando, Mestre, Doutorando, Doutor

Psicologia, Administração, outras

Pesquisa com Desenho, Relato de Experiência

Survey, Experimental e Quase-experimental, Pesquisa-Ação

Quantitativa, Qualitativa, Quali-quanti

Gerar Conhecimento, Instrumento ou Tecnologia

Estudo de Caso, de Amostra (uma organização, várias organizações)

Primária, Secundária

Questionário/Escala, Entrevista, Observação, Análise Documental, Testes/Prova, outros.

Estatística Inferencial, Descritiva, Análise de Conteúdo

Privado, Público, Terceiro Setor, Misto

Primário, Secundário, Terciário

acolhimentos diferenciados nos periódicos aqui analisados (Tabela 7). Como já tinha sido anteriormente mencionado, com base em revisões anteriores, a divulgação foi maior em periódicos vinculados à administração, exceto no caso da rPOT. As categorias "afeto", "cultura", "bem-estar e saúde" e "interações sociais" foram mais divulgadas em periódicos vinculados à psicologia. As categorias "aprendizagem", "contratos psicológicos", "cognição" e "identidade e significado" foram mais divulgadas em periódicos vinculados à administração.

A análise dos artigos lidos nesses periódicos, com base nos critérios apresentados na Tabela 6 , ainda permitiu verificar para que e como os estudos foram feitos e quais seriam os seus beneficiários potenciais. Os resultados estão sintetizados nas Figuras 12 a 18.

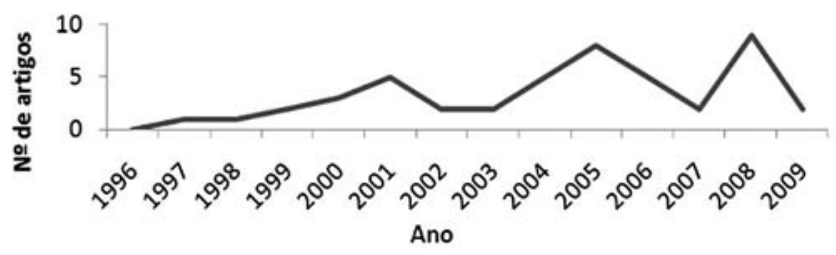

Figura 4. Artigos sobre interações sociais nas equipes e nas organizações encontrados em 14 periódicos nacionais de administração e psicologia. 


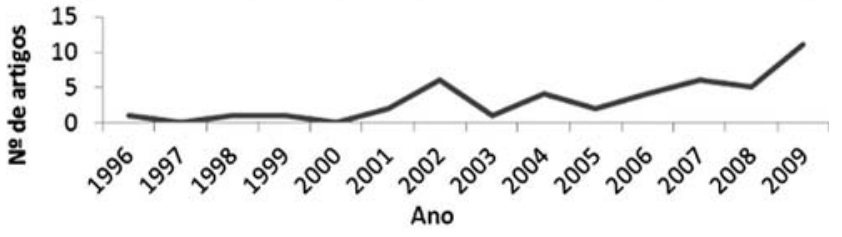

Figura 5. Artigos sobre bem-estar e saúde no trabalho encontrados em 14 periódicos nacionais de administração e psicologia.

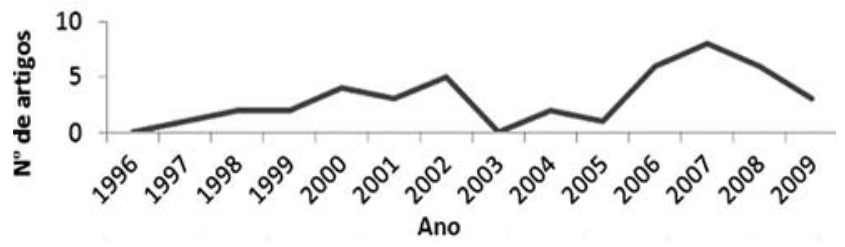

Figura 6. Artigos sobre identidade e significados do trabalho e de seus produtos encontrados em 14 periódicos nacionais de administração e Dsicologia.

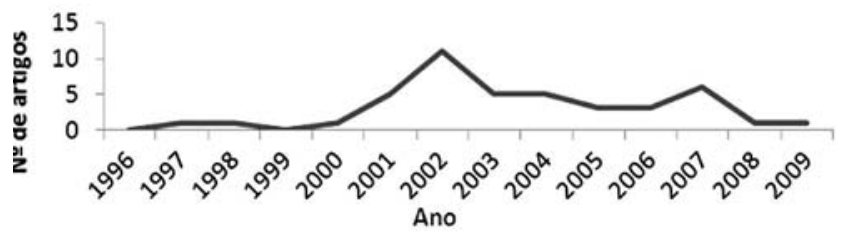

Figura 7. Artigos sobre cognição no trabalho encontrados em 14 periódicos nacionais de administração e psicologia.

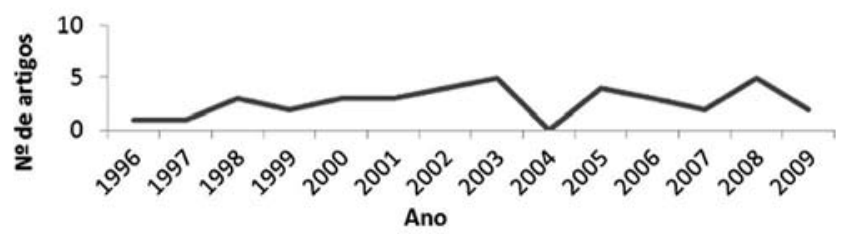

Figura 8. Artigos sobre contratos psicológicos no trabalho encontrados em 14 periódicos nacionais de administração e psicologia.

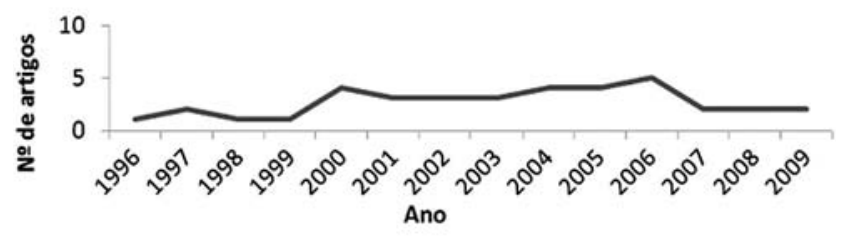

Figura 9. Artigos sobre atitudes frente a mudanças organizacionais encontrados em 14 periódicos nacionais de administração e psicologia.

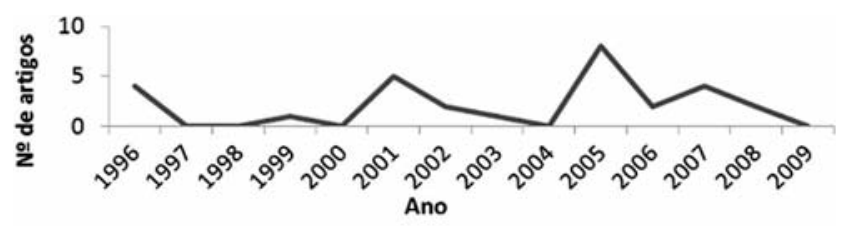

Figura 10. Artigos sobre desempenho produtivo de indivíduos, gerentes e equipes no trabalho encontrados em 14 periódicos nacionais de administração e psicologia.

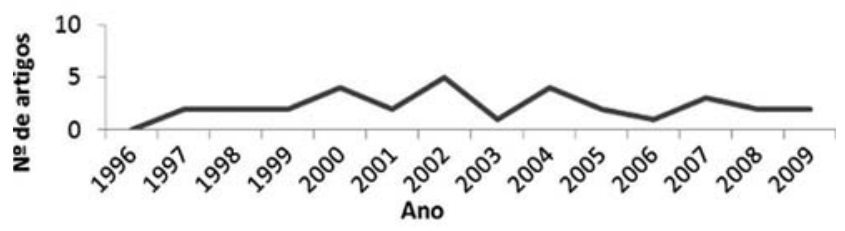

Figura 11. Artigos sobre cultura organizacional encontrados em 14 periódicos nacionais de administração e psicologia.

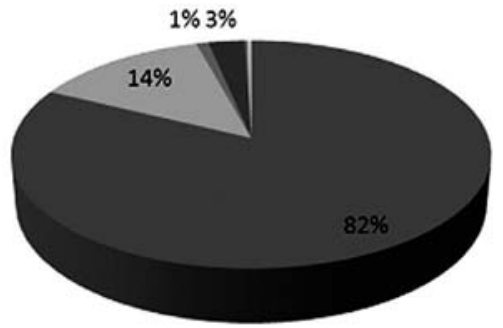

- Gerar conhecimento (1)

Gerar instrumento(2)

= Gerar tecnologia (3)

- Gerar conhecimento e instrumento (4)

a Gerar instrumento $\mathrm{e}$ tecnologia (5)

Eerar conhecimento tecnologia (6)

Figura 12. Finalidades das pesquisas sobre CO relatadas em 14 periódicos nacionais de administração e psicologia.

Os resultados da Figura 12 sugerem que o perfil geral da pesquisa sobre $\mathrm{CO}$, revisada nos 14 periódicos mencionados, nos anos de 1996 a 2009, foi fundamentalmente para gerar conhecimentos. Em segundo lugar, ela pretendeu gerar instrumentos, que geralmente foram escalas de medida.

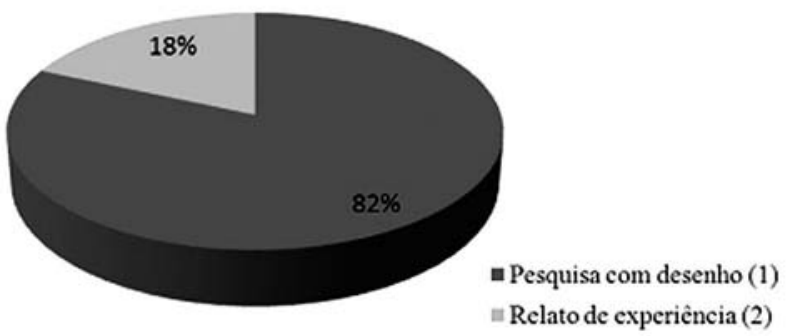

Figura 13. Desenhos de investigação utilizados nas pesquisas sobre CO relatadas em 14 periódicos nacionais de administração e psicologia.

A pesquisa sobre CO deixou de lado os relatos de experiências, bastante comuns nas décadas anteriores aos anos de 1990 (Figura 13). A presença predominante desses relatos, nesses anos do século passado, foi provavelmente consequência da pouca expressividade de linhas de pesquisa consolidadas em programas de pós-graduação. Um passo importante para este amadurecimento foi a formulação de desenhos de investigação em projetos de pesquisa inseridos em linhas de pesquisa.

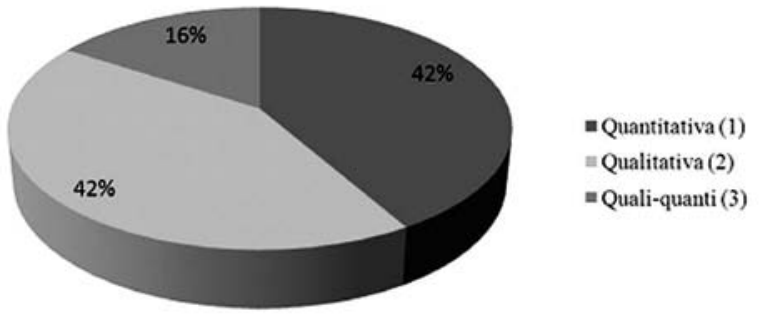

Figura 14. Abordagens metodológicas utilizadas nas pesquisas sobre $\mathrm{CO}$ relatadas em 14 periódicos nacionais de administração e psicologia.

Esses projetos ora adotaram abordagens metodológicas quantitativas, ora abordagens qualitativas, em números equivalentes (Figura 14). Mas também combinaram essas abordagens. Provavelmente em decorrência dessas escolhas, utilizaram questionários ou entrevistas e observação para coletar seus dados (Figura 15) e análises inferenciais ou descritivas e de conteúdo para tratá-los (Figura 16). 
Tabela 7. Categorias de variável critério, relativas ao fazer humano no trabalho, mais frequentemente divulgadas nos periódicos científicos analisados.

\begin{tabular}{|c|c|c|}
\hline Periódicos & Quantidade & Categoria mais frequente \\
\hline RAC & 57 & Aprendizagem \\
\hline rPOT & 55 & Afeto \\
\hline RAUSP & 46 & Contratos psicológicos \\
\hline RAP & 46 & Cognição \\
\hline O\&S & 45 & Cognição \\
\hline ERA & 28 & Identidade e significados \\
\hline Psicologia: Teoria e Pesquisa & 26 & Afeto \\
\hline Psicologia em Estudo & 25 & Afeto \\
\hline Psicologia: Ciência e Profissão & 24 & Cultura \\
\hline Estudos Psic (PUCCAMP) & 17 & Aprendizagem \\
\hline Estudos Psic (UFRN) & 16 & Bem-estar e saúde \\
\hline PSICO-USF & 16 & Cognição \\
\hline Psicologia: Reflexão e Crítica & 14 & Interações sociais \\
\hline PSICO-PUCRS & 8 & Afeto \\
\hline
\end{tabular}

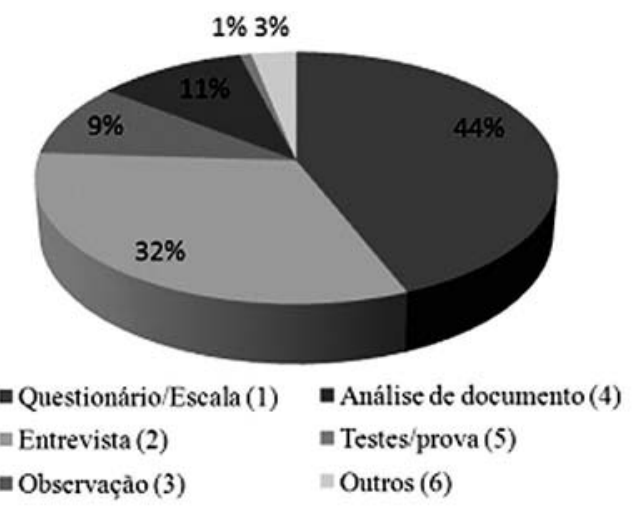

Figura 15. Procedimentos de coleta de dados utilizados nas pesquisas sobre CO relatadas em 14 periódicos nacionais de administração e psicologia.

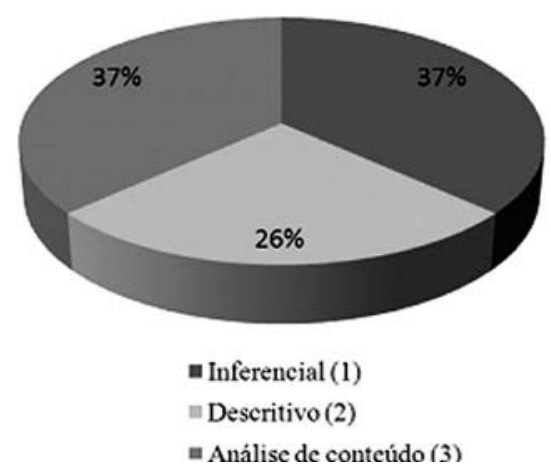

Figura 16. Procedimentos de análise de dados utilizados nas pesquisas sobre CO relatadas em 14 periódicos nacionais de administração e psicologia.
Os estudos sobre CO aqui revisados parece terem igualmente beneficiado os setores público e privado da economia (Figura 17). O terceiro setor ficou bastante prejudicado, no que tange à possibilidade de ser investigado e, consequentemente, de poder incorporar conhecimentos às suas práticas. A Figura 18 deixa claro que o segmento dessa economia, de longe o maior beneficiário, foi o terciário, confirmando o que já se sabia: a PT\&O não é "industrial" e efetivamente não mais deve ter esse adjetivo para qualificá-la enquanto subárea. Ela tem seus objetos de estudos principalmente em organizações de serviço. Não é surpresa a pouca presença do segmento primário, pois ele nunca foi contexto para muitas pesquisas em PO\&T.

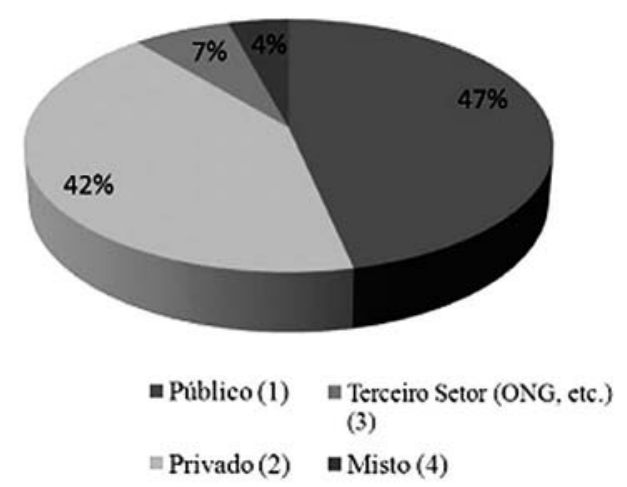

Figura 17. Setores da economia estudados, nas pesquisas sobre CO relatadas em 14 periódicos nacionais de administração e psicologia. 


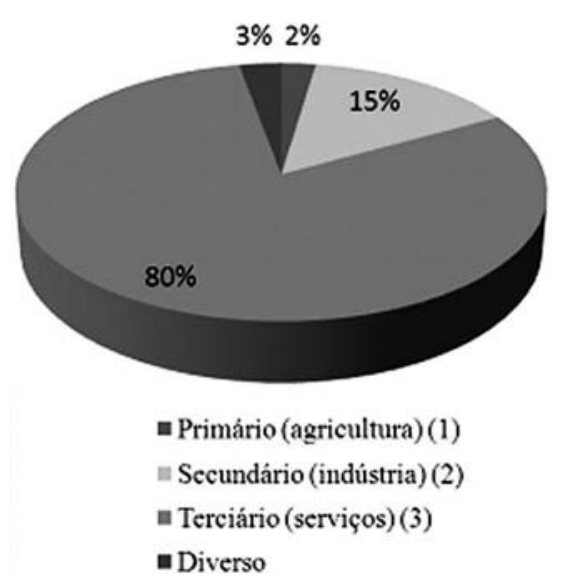

Figura 18. Segmentos da economia estudados, nas pesquisas sobre CO relatadas em 14 periódicos nacionais de administração e psicologia.

\section{Pesquisa sobre Gestão de Pessoas}

Revisões focadas na pesquisa sobre gestão de pessoas, nos volumes do "Annual Review of Psychology", emergiram no final da década de 1960. Estiveram inicialmente interessadas no tema seleção de pessoal, logo seguidas pelo tema T\&D. Somente na década de 1990 apareceram revisões nesses volumes, voltadas para AD. No século passado, a pesquisa sobre esses três temas levou a revisões que sistematizaram o conhecimento então produzido em período anterior à pesquisa sobre CO. Entretanto, não ocorreu um movimento similar ao que aconteceu com esta última, em relação a um investimento na criação de uma disciplina independente, a tentativas de definição sistemática de seus objetos de estudo e a proposições de níveis nos quais sua investigação poderia ser efetuada.

Em gestão de pessoas não foi desenvolvido um quadro teórico geral de referências equivalente àquele já consolidado para CO, descrito na seção anterior. A inexistência da consolidação de uma disciplina voltada para a gestão de pessoas pode ser atribuída à fragmentação das influências tradicionalmente advindas da psicologia, presentes em seus principais temas desde a metade do século passado. Por exemplo: psicometria em seleção e AD; psicologia cognitiva em $\mathrm{AD}$ e T\&D. Em CO, a presença de teorias originárias da psicologia social foi bem maior.

Em seguida, serão resumidas três revisões recentes sobre seleção, $A D$ e T\&D, para demarcação das tendências recentes internacionais. Uma dessas tendências, que poderá ser notada a seguir, é concernente a um possível maior distanciamento da psicometria e da psicologia instrucional, compensado por uma aproximação com teorias advindas das ciências sociais aplicadas.

Foi substancialmente elevada, desde a virada do século, a capacidade de predizer e formular os prováveis resultados de um determinado sistema de seleção, segundo Sackett e Lievens (2008). Isso teria decorrido de cinco melhorias, apontados por esses autores: (1) na qualidade e quantidade das sínteses meta-analíticas, que possibilitaram um melhor entendimento do relacionamento entre preditores ou entre preditores e a variável critério; (2) no entendimento sobre o ganho incremental resultante da adição de um ou mais novos indicadores em um sistema de predição existente; (3) nas correções para estimar validade com base em amostras; (4) no entendimento do impacto adverso na seleção relativo às avaliações de grupos minoritários e majoritários; (5) na identificação de características que moderam ou mediam relações entre variáveis preditoras e critério.

Sackett e Lievens (2008) identificaram vários caminhos com potencial para melhorar a magnitude do relacionamento entre a variável preditora e a variável critério em seleção de pessoal. Dentre eles, a contextualização dos indicadores e o uso de medidas implícitas, que possibilitam fazer inferências sobre construtos por meios indiretos e o papel do tempo na mensuração da variável critério. Novas variáveis critério para validação de sistemas de seleção, decorrentes de contextos organizacionais dinâmicos, teriam sido estudadas: resolução criativa de problemas, capacidade de lidar com situações de trabalho incertas e adaptabilidade transcultural e interpessoal. Avanços também teriam ocorrido na compreensão de medidas de reações de candidatos e de consequências dessas reações e de obstáculos ao uso de sistemas de seleção, como percepções errôneas dos gerentes sobre tais sistemas.

Depois de um período de sete anos sem publicações sobre AD nos volumes do "Annual Review of Psyhology", Rynes, Gerhart e Parks (2005) revisaram a literatura sobre $\mathrm{AD}$ atrelada a recompensas. Eles salientam que, apesar das pesquisas sobre recompensas terem levado a uma extensa literatura em psicologia, poucas pesquisas examinaram as consequências de relacionar pagamento a $\mathrm{AD}$, em contextos de trabalho. Tais autores analisaram, pois, pesquisas recentes sobre avaliação 360 graus e sobre sistemas de "pagamento por desempenho", tais como pagamento por mérito e incentivos individuais e grupais. Na maior parte das organizações, segundo eles, a $\mathrm{AD}$ é usada tanto para fornecer feedback adequado, quanto para motivar. Entretanto, a pesquisa em psicologia tem primariamente investigado o primeiro aspecto e esquecido o segundo.

Quando se trata de remuneração, um dos maiores desafios é garantir que os sistemas de pagamento não estejam motivando comportamentos não adequados. A psicologia teria potencial para contribuir com problemas práticos enfrentados pelos gestores que querem entender os caminhos mais efetivos para avaliar, desenvolver e recompensar pessoas. Entretanto, para ser eficaz, tal contribuição deveria considerar, por exemplo, que recompensas monetárias e motivação intrínseca podem não produzir efeitos opostos ou que o desempenho melhora depois de feedback negativo. Tais questões deveriam ser objeto de mais investigação, de acordo com Rynes e cols. (2005).

Os benefícios de $\mathrm{T} \& \mathrm{D}$ para indivíduos, equipes, organizações e sociedade foram revisados por Aguinis e Kraiger (2009), que também identificaram as condições que maximizam tais benefícios. Estes podem incluir melhoria no desempenho individual e em variáveis que se relacionam a ele, seja diretamente (e.g., inovação e habilidades tácitas, expertise adaptativa, habilidades técnicas e de automonitoramento, ajustamento transcultural) ou indiretamente (e.g., empoderamento, comunicação, planejamento e coordenação de tarefas nas equipes). Também podem incluir benefícios para a melhoria do desempenho organizacional (e.g., rentabilidade, lucratividade, efetividade, produtividade, receita 
por empregado) e para outros resultados ligados diretamente a esse desempenho (e.g., redução de custos, melhoria da qualidade e da quantidade) ou indiretamente (e.g., turnover, reputação da organização, capital social).

Dentre os temas sugeridos pelos autores para pesquisas futuras em T\&D, estão aqueles voltados a entender os fatores que facilitam a transferência de benefícios entre os níveis individual, de equipes e organizacional; estudos com foco na verificação do ciclo de tempo necessário para avaliar a efetividade de T\&D; e pesquisas com o objetivo de identificar fatores que possam acelerar o usufruto dos benefícios nos seus vários níveis. Embora muito se saiba sobre o relacionamento entre satisfação com T\&D e aprendizagem, houve pouca atenção dedicada ao relacionamento entre esta e estados afetivos. Finalmente, segundo Aguinis e Kraiger (2009), existe a necessidade de estudar moderadores situacionais e individuais da aprendizagem e sua transferência; investigar motivação e esforço cognitivo em T\&D. Esses autores concluem que um importante desafio prático para a área de T\&D é integrá-la à seleção de pessoal, gestão do desempenho, recompensas e outras práticas relativas à gestão de pessoas.

O que pode ser dito sobre a pesquisa nacional em gestão de pessoas? Para responder esta pergunta, lamentavelmente foi impossível contar com uma única base de dados como aquela existente em $\mathrm{CO}$ e utilizada para revisar os estudos sobre o fazer humano no trabalho no Brasil. Felizmente, levantamentos igualmente sistematizados foram recentemente utilizados por quatro autores para revisar a produção científica nacional: Queiroga (2009), em seleção de pessoal; Coelho Jr (2009), em AD; Ferreira (2009) e Pereira (2009), em T\&D. Embora tenham feito suas revisões em temáticas relacionadas a gestão de pessoas, esses autores foram treinados para fazer revisões sistemáticas de literatura na Disciplina Comportamento Organizacional (2010) e seguiram os pressupostos gerais desse método, quando realizaram seus levantamentos e análises. Portanto, serão aqui resumidos os seus principais achados.

Após realizar amplo levantamento sobre relatos de pesquisas com o foco em seleção de pessoal, nas bases Scopus, Scielo e Google Acadêmico, Queiroga (2009) encontrou somente 19 textos publicados desde 1990, sendo seis em periódicos científicos de psicologia, um em periódico de administração e o restante em anais completos de congressos científicos e em monografias e dissertações de pós-graduação. Isto é, apesar de ampliar sobremaneira o universo do seu levantamento, quando comparado ao universo de meios de divulgação utilizados para o que foi revisado na seção anterior, a mencionada autora encontrou um número bastante inexpressivo de relatos de pesquisa: menos de dois por ano. Os focos dessas investigações foram em seleção como somente um elemento de estudos mais amplos sobre gestão de pessoas em geral.

A análise da revisão feita por Queiroga (2009) deixa evidente que provavelmente não há linhas de pesquisa produtivas, nos programas de pós-graduação nacionais, dedicadas a gerar conhecimento sobre seleção de pessoal. Há ainda pesquisas que se dedicaram a parâmetros e instrumentos para avaliar competências e muitas descrições e reflexões sobre práticas de seleção. Entretanto, falta sistematização aos estudos que descrevem desenhos de investigação, como foi diagnosticado como sendo a tendência dominante em CO, na seção anterior. A autora finaliza argumentando que existe pouca ênfase em validade preditiva, em efeitos de seleção no desempenho e nas relações entre seleção e contexto. Considerando que seleção ainda é um campo de intervenção com forte presença de profissionais e que a produção internacional sobre esta temática teve forte desenvolvimento nas últimas décadas, como foi anteriormente apontado, o que pode ser concluído é que tudo está por ser feito no Brasil.

Coelho Jr (2009) verificou um quadro similar quando revisou a produção nacional sobre AD. Encontrou 27 relatos completos de pesquisas divulgados entre 1990 e 2008, em anais de congressos e em periódicos de psicologia e administração. Nestes, predomina a descrição de uma ampla variedade de medidas objetivas e subjetivas, geralmente apropriadas só para o nível individual de análise. $\mathrm{O}$ foco da pesquisa é principalmente na etapa de avaliar, existindo grandes lacunas nos estudos com foco nas etapas de planejamento, acompanhamento e revisão de desempenho. Pouca ênfase foi dada nas dimensões psicológicas dos antecedentes do desempenho que é avaliado e mais ênfase foi dada nos resultados da avaliação.

AAD é um campo de intervenção com forte presença profissional no Brasil, aparentemente maior até que o de seleção nos dias atuais, conforme os dados apresentados no início do presente texto. Mas sua produção nacional de conhecimento deixa muito a desejar. Sua produção internacional não foi tão expressiva e sistemática quanto à realizada em seleção de pessoal. Portanto, em termos relativos, não há muito em que buscar apoio científico, aqui ou fora daqui. A conclusão parece ser que a situação de seleção de pessoal ainda é melhor do que a situação da produção em AD. Ambas, no entanto, são muito ruins.

Numa revisão focada na primeira etapa de T\&D, a avaliação de necessidades, Ferreira (2009) encontrou poucos relatos nacionais de pesquisa. Mesmo assim, sua apreciação é de que ocorreram consideráveis avanços: (1) metodológicos - por conta da diversificação de técnicas de coleta de dados no nível micro e incorporação de análises macro; e (2) teóricos - pela adoção do conceito de competências, pela consideração dos fatores de contexto e de processos organizacionais. $\mathrm{O}$ autor argumenta que faltam modelos teórico-metodológicos que incorporem esses avanços, adotem a abordagem multinível e concebam o contexto como antecedente e consequente. Borges-Andrade e Abbad (1996) diagnosticaram que a produção nacional era pobre, especialmente no que tangia à produção de conhecimentos sobre planejamento e execução em T\&D, etapas depois da avaliação de necessidades, em gestão de pessoas. Passados 14 anos, esse quadro não foi alterado, mas é bem diferente o que ocorreu com a última etapa de T\&D, como será descrito a seguir.

Ocorreu intenso crescimento de estudos publicados sobre avaliação de T\&D no Brasil, com o número total alcançando 42 relatos de pesquisas entre 1990 e 2008 (Pereira, 2009). Além de quantitativo, o salto foi qualitativo, pois foi sistematicamente baseado em alguns quadros teóricos de referências. Boa parte desse crescimento foi consequência do apoio generoso de órgãos de fomento a um programa de pesquisa coordenado pela Universidade de Brasília e realizado nesta e em outras três instituições públicas federais dos estados 
de Minas Gerais e Bahia. No entanto, nos últimos anos foi iniciado um espalhamento dessa produção por universidades de outras naturezas e em outras unidades da federação.

Pereira (2009) constatou, em sua revisão, uma ampla e diversificada quantidade de medidas de avaliação validadas sobre insumos, procedimentos, processos, ambiente organizacional e efeitos de T\&D nesse ambiente, no nível individual. Diagnosticou um conhecimento solidificado sobre variáveis preditoras desses efeitos, especialmente variáveis externas (contexto organizacional) ao T\&D e não internas (planejamento e execução) a este. Descreveu pesquisas realizadas em organizações públicas e privadas, utilizando medidas padronizadas e análise de regressão múltipla dos dados. Entretanto, argumentou que não ocorreram iguais avanços quanto a efeitos relativos à aprendizagem em $T \& D$ e quanto a efeitos no ambiente organizacional, nos níveis não individuais.

A pesquisa sobre gestão de pessoas parece não ter conseguido alcançar os padrões da pesquisa sobre o fazer humano no trabalho. Esta, quando comparada com aquela, dispõe de referenciais que permitem um enquadramento mais fácil do conhecimento produzido e foi mais profícua, tanto no cenário nacional quanto internacional. A pesquisa sobre gestão de pessoas, no cenário nacional, não conseguiu acompanhar o desenvolvimento internacional, especialmente no que tange a seleção e AD. Esta, mesmo no cenário internacional, deixa a desejar em termos quantitativos e qualitativos, quando comparada ao que se passou com seleção (nos EUA) e T\&D (em muitos países do mundo). A situação de T\&D, no cenário nacional, já permite uma apreciação mais otimista.

\section{Uma Agenda Estratégica para a Pesquisa Nacional}

Os dados analisados na presente revisão de literatura trazem algumas limitações. Foram coletados e organizados com base em artigos completos publicados em periódicos e, em alguns casos, em anais de congressos que publicam textos completos. Embora minoritária, pode ser que a produção intelectual divulgada em livros tenha características não equivalentes a esta. Além disto, não foi possível seguir exatamente os mesmos métodos sistemáticos de revisão de literatura sobre o fazer humano no trabalho e sobre gestão de pessoas. Tampouco foi possível sempre considerar períodos equivalentes de tempo e uma base comum de periódicos nacionais, para efetuar as análises, embora esses períodos tenham sobreposições razoáveis e sejam de pelo menos 14 anos e tais periódicos sempre incluírem a psicologia e a administração, áreas que acolhem artigos científicos sobre PO\&T e PT\&O, como há muito é sabido.

Uma outra limitação foi que parte dos dados foi analisada pelos autores desta revisão, outra parte foi publicada por outros autores e aqui sintetizada e comparada com aqueles. Todos esses autores, contudo, seguiram um método sistemático de revisão de literatura que tem sido utilizado para formar pesquisadores e organizar conhecimento no Programa de Pós-graduação em Psicologia Social, do Trabalho e das Organizações da Universidade de Brasília (Disciplina Comportamento Organizacional, 2010), o que sugere a existência de uma mínima padronização metodológica. Assim, é possí- vel formular uma breve proposta de agenda estratégica para a pesquisa nacional, de modo a promover o desenvolvimento da subárea de $\mathrm{PT} \& \mathrm{O}$ ou PO\&T nas próximas décadas.

A construção de medidas e testes de modelos de predição são necessários, especialmente na pesquisa sobre clima, desvios de comportamento, tomada de decisão e julgamentos, motivação, fuga e esquiva, criatividade e solução de problemas (fatores humanos no trabalho) e sobre seleção e avaliação de desempenho (gestão de pessoas). Essa pesquisa deve adquirir a competência teórico-metodológica demonstrada por aquela feita com objetos de estudo como valores, contratos psicológicos, aprendizagem, percepção de justiça e equidade e TD\&E. Seus pesquisadores devem criar redes como as existentes entre pesquisadores desses objetos de estudo. Em gestão de pessoas, é necessária a diversificação de temas e de referências advindas de outras áreas do conhecimento.

Para explorar temas novos, em toda a subárea, será preciso utilizar estudos descritivos com pequenas amostras. Mas, para aprofundar temas conhecidos, será preciso mais cuidado com a representatividade das amostras. Grupos consolidados precisam ousar investigar temáticas fora do que habitualmente fazem. A subárea deve intensificar estudos no nível meso e utilizar a abordagem multinível. Estudos inferenciais, com desenhos quase-experimental ou experimental e de corte longitudinal, devem ser utilizados com mais frequência. Dados precisam ser coletados com mais de um método. Fenômenos da subárea precisam ser estudados no terceiro setor e no segmento primário da economia.

A produção intelectual de PT\&O ou PO\&T precisa ser mais divulgada por meio de veículos dela própria e da psicologia, sem abandonar os veículos da administração. Seus autores também devem citar artigos nacionais. Esta produção precisa ser mais bem distribuída entre autores e estes devem mantê-la ao longo de suas vidas. Docentes devem ser estimulados a cooperar, para desenvolver artigos. É preciso, de uma vez por todas, compreender redes como uma forma privilegiada de produção intelectual. Finalmente, além de ser divulgada em periódicos científicos, esta produção precisará ser "traduzida", para ser compreendida por audiências formadas por gestores, trabalhadores e público em geral, e disseminada em meios que alcancem tais audiências com ligeireza e singeleza.

\section{Referências}

Aguinis, H, \& Kraiger, K. (2009). Benefits of training and development for individuals and teams, organizations, and society. Annual Review of Psychology, 60, 451-474.

Associação Brasileira de Psicologia Organizacional e do Trabalho - SBPOT (2010). Pós-graduação stricto sensu. Retirado em 15/08/ 2010, de http://www.sbpot.org.br/.

Associação Nacional de Pesquisa e Pós-graduação em Psicologia - ANPEPP (2010). Pós-graduação. Retirado em 15/08/2010, de http://www.anpepp.org.br/index-pos.htm.

Austin, J. T., Scherbaum, C. A., \& Mahlman, R. A. (2002). History of research methods in industrial and organizational psychology: Measurement, design, analysis. Em S. G. Rogelberg (Ed.), Handbook of research methods in industrial and organizational psychology (pp. 3-33). Oxford: Blackwell Publishing. 
Borges-Andrade, J. E. (2001). Seminário nacional "PósGraduação: enfrentando novos desafios - Psicologia". Infocapes, 9, 141-148.

Borges-Andrade, J. E., \& Abbad, G. S. (1996). Treinamento e desenvolvimento: reflexões sobre suas pesquisas científicas. Revista de Administração da USP, 31, 112-125.

Borges-Andrade, J. E., Coelho Jr. F. A., \& Queiroga, F. (2006). Pesquisa sobre micro comportamento organizacional no Brasil: o estado da arte. Em Sociedade Brasileira de Psicologia Organizacional e do Trabalho (Org.), Anais eletrônicos do II Congresso Brasileiro de Psicologia Organizacional e do Trabalho. Brasília: SBPOT.

Borges-Andrade, J. E., \& Meira, M. (2003). As pesquisas sobre comportamento organizacional no Brasil. Em Universidade Federal da Paraíba (Org.), Anais do III Congresso Norte-Nordeste de Psicologia. João Pessoa: ANPEPP.

Borges-Andrade, J. E., \& Zanelli, J. C. (2004). Psicologia e produção de conhecimento em organizações e trabalho. Em J. C. Zanelli, J. E. Borges-Andrade \& A. V. B. Bastos (Eds.), Psicologia, organizações e trabalho no Brasil (pp. 492-517). Porto Alegre: Artmed.

Brief, A. P., \& Weiss, H. M. (2002). Organizational behavior: Affect in the workplace. Annual Review of Psychology, 53, 279-307.

Coelho Jr., F. A. (2009). Suporte à aprendizagem, satisfação no trabalho e desempenho: um estudo multinível. Tese de Doutorado, Universidade de Brasília, Brasília.

Coelho Jr., F. A., \& Borges-Andrade, J. E. (2004). Percepção de cultura organizacional: uma análise empírica da produção científica brasileira. Psico-USF, 9, 191-199.

Disciplina Comportamento Organizacional (2010). Planilha de registro da produção intelectual em periódicos nacionais, 19962009. Brasília: Programa de Pós-graduação em Psicologia Social, do Trabalho e das Organizações, Universidade de Brasília.

Féres-Carneiro, T., Bastos, A. V., Feitosa, M. A. G., Seidlde-Moura, M. L., \& Yamamoto, O. H. (2010). Lacunas, metas e condições para a expansão da pós-graduação em psicologia no país. Psicologia: Reflexão e Crítica, 23, 11-24.

Ferreira, R. R. (2009). Avaliação de necessidades de treinamento: proposição e aplicação de um modelo teóricometodológico nos níveis macro e meso-organizacionais. Dissertação de Mestrado, Universidade de Brasília, Brasília.

Gelfand, M. J., Erez, M., \& Aycan, Z. (2007). Cross-cultural organizational behavior. Annual Review of Psychology, 58, 479-514.

Gondim, S. M. G. (2009, maio). Psicólogos organizacionais e do trabalho. Trabalho apresentado no $6^{\circ}$ Congresso Norte-Nordeste de Psicologia, Belém.

Gondim, S. M. G., \& Bastos, A. V. B (2010). O trabalho do psicólogo no Brasil. Porto Alegre: Artmed.

Hodgkinson, G. P., \& Healey, M. P. (2008). Cognition in organizations. Annual Review of Psychology, 59, 387-417.
Hutz, C. S., Rocha, M. L. R., Spink, M. J. P., \& Menandro, P. R. M. (2010). Perfil, avaliação e metas de produção intelectual dos programas de pós-graduação em psicologia. Psicologia: Reflexão e Crítica, 23, 25-34.

Lo Bianco, A. C, Almeida, S. S., Koller, S. H., \& Paiva, V. (2010). A internacionalização dos programas de pós-graduação em psicologia: perfil e metas de qualificação. Psicologia: Reflexão e Crítica, 23, 1-10.

O’Reilly, C. A. (1991). Organizational behavior: Where we've been, where we're going. Annual Review of Psychology, 42, 427458.

Pereira, S. C. M. (2009). Avaliação, com base em modelo lógico, de efeitos de um treinamento estratégico no desempenho de egressos e da organização. Dissertação de Mestrado, Universidade de Brasília, Brasília.

Queiroga, F. (2009). Seleção de pessoas e desempenho no trabalho: um estudo sobre a validade preditiva dos testes de conhecimentos. Tese de Doutorado, Universidade de Brasília, Brasília.

Rynes, S. L., Gerhart, B., \& Parks, L. (2005). Personnel psychology: Performance evaluation and pay-for performance. Annual Review of Psychology, 56, 571-600.

Rossoni, L. (2006). A dinâmica de relações no campo da pesquisa em organizações e estratégia no Brasil: uma análise institucional. Dissertação de Mestrado, Universidade Federal do Paraná, Curitiba.

Rousseau, D. M. (1997). Organizational behavior in the new organizational era. Annual Review of Psychology, 48, 515-546.

Sackett, P. R., \& Lievens, F. (2008). Personnel selection. Annual Review of Psychology, 59, 419-450.

Siqueira, M. M. M. (2002). Medidas do comportamento organizacional. Estudos de Psicologia, 7, 11-18.

Souza, M. G. S., Vasconcelos, L. C., \& Borges-Andrade, J. E. (2009). Pesquisa sobre mudança nas organizações: a produção brasileira em micro comportamento organizacional. Psicologia: Organizações e Trabalho, 9, 32-46.

Staw, B. M. (1984). Organizational behavior: A review and reformulation of the field's outcome variables. Annual Review of Psychology, 35, 627-666.

Tonetto, A. M., Amazarray, M. R., Koller, S. H., \& Gomes, W. B. (2008). Psicologia Organizacional e do Trabalho no Brasil: desenvolvimento científico contemporâneo. Psicologia \& Sociedade, 20, 165-173.

Wilpert, B. (1995). Organizational behavior. Annual Review of Psychology, 46, 59-90.

Zanelli, J. C., \& Bastos, A. V. B. (2004). Inserção profissional do psicólogo em organizações e no trabalho. Em J. C. Zanelli, J. E. Borges-Andrade \& A. V. B. Bastos (Eds.), Psicologia, organizações e trabalho no Brasil (pp. 466-491). Porto Alegre: Artmed. 